\title{
Prevalence and Patterns of Male Infertility Based on Semen Analysis in Patients Visiting Massawa Hospital; Eritrea: Cross-Sectional Study; 2020
}

Berhe Tesfai ( $\sim$ berhetesfai04@gmail.com )

Ministry of Health https://orcid.org/0000-0003-1820-7395

Fitsum Kibreab

Ministry of Health

Hailemichael Gebremariam

Ministry of Health

Liwam Abraham

Ministry of Health

\section{Research}

Keywords: Infertility, male factor, primary, secondary, sperm

Posted Date: April 13th, 2021

DOl: https://doi.org/10.21203/rs.3.rs-401307/v1

License: (c) (i) This work is licensed under a Creative Commons Attribution 4.0 International License. Read Full License 


\section{Abstract \\ Background}

Semen analysis is the first step to identify male factor infertility. World Health Organization estimates that male factor accounts for $50 \%$ of couple sub-fertility. The objective of this study was to determine the prevalence and patterns of male factor infertility based on semen analysis in patients visiting Massawa Hospital with infertility complaints.

\section{Methods}

It was a retrospective, descriptive cross sectional hospital based type of study with a census sampling method. Patient's medical records and hospital laboratory register were used to retrieve semen analysis results of patients from June 2018 to June 2020. Ethical approval was obtained from the Ministry of Health Research and Ethical Review Committee. Confidentiality of patients records kept was secured and consent was obtained from study participants to use their data. Results were presented in frequency, tables and $p$ value $<0.05$ was considered significant.

\section{Results}

A total of 112 patients data was analyzed in the study with $49.1 \%$ were aged between 20 to 30 years. The prevalence of male factor infertility in these patients was found to be $42 \%$ and $79.5 \%$ of them had primary type of infertility. Of the study participants; 63 (56.3\%), 72 (64.3\%) and 70 (62.5\%) had sperm count $<15$ million sperms $/ \mathrm{ml}$, sperm motility $<40 \%$ and morphology of $<60 \%$ respectively. One tenth, 15 $(13.4 \%)$ of the patients had a semen volume of $<1.5 \mathrm{ml} /$ ejaculate, out of which $13(86.7 \%)$ had primary type of infertility. Moreover; $72(64.3 \%)$ patients had total sperm count/ejaculate of $<39$ million and 59 (82\%) of these had primary type of infertility. In addition; $50.8 \%$ and $50 \%$ of patients aged 20 to 30 years had a sperm count $<15$ million $/ \mathrm{ml}$ and sperm motility of $<40 \%$ respectively.

\section{Conclusion}

The prevalence of male factor infertility was slightly higher and was dominated with primary infertility. Most patients had lower sperm count, sperm motility but higher semen volume, and majority of the patients with abnormal sperm results were aged between 20 to 30 years. Further prospective researches to determine the risk factors for male infertility and introducing assisted type of fertility in Eritrea are highly recommended.

\section{Plain English Summary}


Male infertility refers to a male's inability to result pregnancy in a fertile female and semen quality is used as a surrogate measure of male fecundity. The study was done to evaluate the male infertility prevalence on patients who visited Massawa Hospital due to infertility complains and who did semen analysis for this problem. Semen analysis results were retrieved from the hospital laboratory register and their medical cards.

A total of 112 patient's semen analysis and background characteristics were evaluated and $42 \%$ of them were having semen reference below the World Health Organization lower limits which defines infertility. Two third of them has never born a child before and about half of the patients were aged between 20 to 30 years old. Majority of the patients had sperm count/ml, total sperm count/ejaculate, sperm motility and morphology below the lower reference limit of the World Health Organization. About half of the patients aged 20 to 30 years were infertile. Sperm count, motility and morphology doesn't show significant association to the type of infertility. And, the age of patients were not statistically significant to the sperm count, motility and morphology.

In conclusion; the prevalence of male factor infertility and primary infertility type was slightly higher in these patients. Even though most of the patients had higher semen volume, they had lower sperm count, and sperm motility, and majority of the patients with abnormal sperm results were the young age group (20 to 30) years old.

\section{Background}

According to the World Health Organization (WHO), infertility is the inability to bear a child during a period of one year having regular sexual intercourses without any contraception. Infertility is considered as primary when the couple has never born a child and secondary when it becomes unable to conceive during a 12-month period of trial after having born at least one child in the past. Worldwide, 10 to $15 \%$ of couples are infertile. $[1,2]$

There are no reliable figures for global prevalence of infertility, but as per the WHO estimates 6080 million couples worldwide currently suffer from infertility. It varies across regions of the world and is estimated to affect $8-12 \%$ of couple's worldwide. [3] Male infertility refers to a male's inability to result pregnancy in a fertile female. It is commonly due to deficiencies in the semen, and semen quality is used as a surrogate measure of male fecundity. [4]

Semen analysis is the first step to identify male factor infertility. Standardized methods of semen analysis are available allowing accurate assessment of sperm quality and comparison amongst laboratories. Population based references ranges are available for standard semen and sperm parameters. [5]

Semen quality is a very important factor that reflects male reproductive health. It has been suggested that low semen quality may be a potential contributing factor in reducing fertility rates and increasing number of children born after use of assisted reproductive technology. [6] Males with sperm parameters below the 
WHO normal values are considered to have male factor infertility. The most significant of these are low sperm concentration, poor sperm motility, and abnormal sperm morphology. [5]

The WHO has revised lower reference limits for semen analyses, derived from a study of over 1900 men whose partners had a time-to-pregnancy of $\leq 12$ months. The Volume: $1.5 \mathrm{~mL}$ (95\% Cl: 1.4-1.7), Sperm concentration: 15 million spermatozoa/mL (95\% Cl: 12-16), Total sperm number: 39 million spermatozoa per ejaculate (95\% Cl: 33-46), Morphology: $4 \%$ normal forms (95\% Cl: $3-4)$, and Total (progressive + non-progressive motility): 40\% (95\% Cl: 38-42). [3]

In approximately half of all cases, infertility is caused by male-related factors. In $50 \%$ of childless couples, abnormal sperm parameters are the male infertility factor. However, in $30-40 \%$ of infertile couples, male infertility factors are absent. Over the past 20 years, approximately $30-50 \%$ of cases of infertility are due to male factors, and $20 \%$ of cases are due to a combination of both male and female factors. [7]

During a period of military conflict towards the end of the 1990s, Eritrea experienced a remarkable decline in fertility. An important issue of concern has been whether the decline is driven primarily by the recent border conflict with Ethiopia or by changes in other factors including delay in age at marriage, improvements in child survival and socio-cultural factors that pre-dated the conflict. [8]

To the knowledge of the researchers, the prevalence of infertility in general and the male factor in particular is not determined in Eritrea. Moreover; the patterns and severity of male factor infertility is not identified. Thus the objective of this study was to determine the prevalence and patterns of male factor infertility on these who have infertility complaint based on their semen analysis in Massawa Hospital.

\section{Materials And Methods}

\section{Study design and study population}

This study was a retrospective descriptive, cross-sectional hospital based type and census sampling method was applied. Patient's medical records were reviewed and their semen analysis results were retrieved from their clinical cards and laboratory register of Massawa Hospital. All patients who come to Massawa Hospital outpatient department with a complaint of infertility from June 2018 to June 2020 and did semen analysis were the study population of this research.

\section{Data collection and analysis}

Data collection was conducted in two months duration from June to July, 2020. After retrieving the semen analysis results, the patterns of their semen results were documented and grouped. Other necessary background characteristics as age and type of infertility were also recorded from their medical records. Finally, the data was encoded in word Excel and analyzed by SPSS software. Statistical analysis results were presented in frequency distribution, tables and $p$ value $<0.05$ was considered significant. Patients were grouped according to their sperm analysis results based on sperm count $/ \mathrm{ml}$, total sperm 
count/ejaculate, sperm motility and sperm morphology. They were also grouped on their age, type of infertility and semen volume.

\section{Data interpretation}

Based on the WHO reference values of 2010, the lower limit of the sperm analysis parameters were used as reference values in this research. Sperm count $<15 \mathrm{milliom} / \mathrm{ml}$ and sperm motility $<40 \%$ was used to assess the semen analysis results and to determine the prevalence of the male factor infertility. Thus; patients with semen analysis results below the WHO lower reference values of sperm count and motility was considered infertile. The WHO criteria for the sperm morphology of strict criteria of only $4 \% \mathrm{normal}$ was not used to analysis the sperm morphology results as the procedure of strict criteria was not used during the interpretation by the laboratory technicians. Thus; $60 \%$ sperm morphology was used based on previous national references without using the strict criteria.

\section{Ethical consideration}

Ethical approval was obtained from the Research and Ethical Review Committee of Ministry of Health, Eritrea. The zonal and hospital medical officers were asked permission to conduct the study. The medical records and semen results of the patients was kept secured and information was used as aggregates. Consent was obtained from each study participant to use their data.

\section{Results}

\section{Background of study participants}

A total of 112 patients were enrolled in the study and their medical records and semen analysis results were analyzed. The age distribution of the study participants was $20-30$ years (49.1\%), 21-39 years $(33.9 \%)$ and $>40$ years (17\%). The prevalence of male factor infertility based on semen analysis on patients who come to Massawa Hospital with infertility complaints was $42 \%$ with primary type of infertility predominance (79.5\%). (Table: 1 )

Table: 1 Background of study participants 


\begin{tabular}{|cll|}
\hline Fertility of respondents & Frequency $(\mathrm{N})$ & Percent (\%) \\
\hline Fertile & 65 & 58.0 \\
\hline *Infertile & 47 & 42.0 \\
\hline Type of infertility & & \\
\hline Primary & 89 & 79.5 \\
\hline Secondary & 23 & 20.5 \\
\hline Age of respondents & & \\
\hline $20-30$ & 55 & 49.1 \\
\hline $31-39$ & 38 & 33.9 \\
\hline$>40$ & 19 & 17.0 \\
\hline Total & 112 & 100.0 \\
\hline
\end{tabular}

*Infertile men refers to sperm count of $<15,000,000$ spermatozoa/ml and sperm motility $<40 \%$

\section{Association of sperm analysis results with type of infertility}

Majority of the study participants, $63(56.3 \%)$ had a sperm count of $<15$ million sperms $/ \mathrm{ml}$ and most (84.1\%) of them had primary type of infertility and $14(12.5 \%)$ patients had azoospermia (no single sperm). Generally; 72 (64.3\%) patients had a sperm count of $<20,000,000$ spermatozoa/ml. And, only 15 $(13.4 \%)$ of the patients had a semen volume of $<1.5 \mathrm{ml} /$ ejaculate and $76(67.9 \%)$ of patients with semen volume of $>1.5 \mathrm{ml} /$ ejaculate had primary type of infertility. Two third of the study participants, $72(64.3 \%)$ had a total sperm count of $<39$ million/ejaculate. Even though Primary type of male infertility was predominant with $79.5 \%$, sperm count doesn't show statistically significant association to the type of infertility. Moreover, the study showed that, $72(64.3 \%)$ of the patients had a sperm motility of $<40 \%$, out of which $77.8 \%$ had primary type of infertility. Only $17.5 \%$ of patients with sperm motility of $>40 \%$ had secondary type of infertility. Majority patients; 70 (62.5\%) had sperm morphology of $<60 \%$ from which $75.7 \%$ had primary type of infertility. Sperm motility and morphology doesn't show significant association to their type of infertility. (Table: 2 )

Table: 2; Characteristics of sperm analysis and type of infertility 


\begin{tabular}{|c|c|c|c|c|c|}
\hline \multirow{2}{*}{ Variables } & & \multicolumn{2}{|c|}{ Type of infertility } & \multirow[b]{2}{*}{ Total } & \multirow[b]{2}{*}{$P$ value } \\
\hline & & Primary & Secondary & & \\
\hline \multicolumn{6}{|c|}{ Sperm count of respondents/ml } \\
\hline$<15,000,000 / \mathrm{mL}$ & $\mathrm{N}(\%)$ & $53(84.1)$ & $10(15.9)$ & $63(100.0)$ & \multirow[t]{2}{*}{0.168} \\
\hline$>=15,000,000 / \mathrm{mL}$ & $\mathrm{N}(\%)$ & $36(73.5)$ & $13(26.5)$ & 49(100.0) & \\
\hline \multicolumn{6}{|c|}{ Absolute (total sperm count)/ ejaculate } \\
\hline$<39,000,000 /$ ejaculate & $\mathrm{N}(\%)$ & $59(82)$ & $13(18)$ & $72(100.0)$ & \multirow[b]{2}{*}{0.443} \\
\hline$>39,000,000 /$ ejaculate & $\mathrm{N}(\%)$ & $30(75)$ & $10(25)$ & $40(100.0)$ & \\
\hline \multicolumn{6}{|c|}{ Motility percentage of respondents } \\
\hline$<40 \%$ & $\mathrm{~N}(\%)$ & $56(77.8)$ & $16(22.2)$ & $72(100.0)$ & \multirow[t]{2}{*}{0.550} \\
\hline$>=40 \%$ & $\mathrm{~N}(\%)$ & $33(82.5)$ & $7(17.5)$ & $40(100.0)$ & \\
\hline \multicolumn{6}{|c|}{ Morphology percentage of respondents } \\
\hline$<60 \%$ & $\mathrm{~N}(\%)$ & $53(75.7)$ & $17(24.3)$ & $70(100.0)$ & \multirow[t]{2}{*}{0.196} \\
\hline$>=60 \%$ & $\mathrm{~N}(\%)$ & $36(85.7)$ & $6(14.3)$ & $42(100.0)$ & \\
\hline \multicolumn{6}{|l|}{ Semen volume } \\
\hline$<1.5 \mathrm{ml} /$ ejaculate & N (\%) & 13(86.7) & $2(13.3)$ & $15(100.0)$ & \multirow[b]{2}{*}{0.458} \\
\hline$>=1.5 \mathrm{ml} /$ ejaculate & $\mathrm{N}(\%)$ & 76 (78.4) & $21(21.6)$ & $97(100.0)$ & \\
\hline Total & $N(\%)$ & $89(79.5)$ & $23(20.5)$ & $112(100.0)$ & \\
\hline
\end{tabular}

\section{Association of sperm analysis results with age of respondents}

The age distribution of the patients who had a sperm count of $<15,000,000$ spermatozoa $/ \mathrm{ml}$ was $20-30$ years $(50.8 \%), 31-39(38.1 \%)$ and $>40$ years $(11.1 \%)$. Majority $(64.3 \%)$ of patients had an absolute sperm count of < 39 million spermatozoa/ejaculate more predominant on patients aged 20 - 30 years $(30.4 \%)$. The age of patients doesn't show significant association with sperm count. Only 6(40\%) patients aged 20-30 years had a semen volume of $<1.5 \mathrm{ml} /$ ejaculate and $48(49.5 \%)$ patients had semen volume of $>=1.5 \mathrm{ml} /$ ejaculate on the same age group.

The sperm motility of $<40 \%$ was decreased as $20-30$ years (50\%), 31-39 years $(30.6 \%)$ and $>40$ years with $19.4 \%$. patients aged 20 to 30 years had $48.6 \%$ of sperms with normal morphology of $<60 \%$. Sperm motility and morphology doesn't shoe significant association to the age of the study participants. (Table: 3) 
Table: 3 Characteristics of sperm analysis and age of respondents

\section{Age of respondents (years)}

\begin{tabular}{|c|c|c|c|c|c|c|}
\hline \multicolumn{2}{|c|}{ Variables of sperm analysis } & $20-30$ & $31-39$ & $>40$ & Total & P-value \\
\hline \multicolumn{7}{|l|}{ Sperm count /ml } \\
\hline$<15,000,000 / \mathrm{ml}$ & $\mathrm{N}(\%)$ & $32(50.8)$ & $24(38.1)$ & $7(11.1)$ & $63(100.0)$ & \multirow[b]{2}{*}{0.156} \\
\hline$>=15,000,000 / \mathrm{ml}$ & $\mathrm{N}(\%)$ & $23(46.9)$ & $14(28.6)$ & 12(24.5) & $49(100.0)$ & \\
\hline \multicolumn{7}{|c|}{ Total Sperm count/ejaculate } \\
\hline$<39,000,000$ & $\mathrm{~N}(\%)$ & $34(47.2)$ & $21(29.2)$ & $17(23.6)$ & $72(100.0)$ & \multirow[t]{2}{*}{0.698} \\
\hline$>=39,000,000$ & $\mathrm{~N}(\%)$ & $21(52.5)$ & $11(27.5)$ & $8(20)$ & $40(100.0)$ & \\
\hline \multicolumn{7}{|l|}{ Sperm Motility } \\
\hline$<40 \%$ & $\mathrm{~N}(\%)$ & $36(50.0)$ & $22(30.6)$ & $14(19.4)$ & $72(100.0)$ & \multirow[t]{2}{*}{0.550} \\
\hline$>=40 \%$ & $\mathrm{~N}(\%)$ & $19(47.5)$ & $16(40.0)$ & $5(12.5)$ & $40(100.0)$ & \\
\hline \multicolumn{7}{|l|}{ Sperm Morphology } \\
\hline$<60 \%$ & $\mathrm{~N}(\%)$ & $34(48.6)$ & $20(28.6)$ & $16(22.9)$ & $70(100.0)$ & \multirow[t]{2}{*}{0.052} \\
\hline$>=60 \%$ & $\mathrm{~N}(\%)$ & $21(50.0)$ & $18(42.9)$ & $3(7.1)$ & $42(100.0)$ & \\
\hline \multicolumn{7}{|c|}{ Semen volume/ ejaculate } \\
\hline$<1.5 \mathrm{ml}$ & $\mathrm{N}(\%)$ & $6(40)$ & $5(33.3)$ & $4(26.7)$ & $15(100.0)$ & \multirow{3}{*}{0.534} \\
\hline$>=1.5 \mathrm{ml}$ & $N(\%)$ & $48(49.5)$ & $27(27.8)$ & $22(22.7)$ & $97(100.0)$ & \\
\hline Total & $N(\%)$ & $55(49.1)$ & $38(33.9)$ & $19(17.0)$ & $112(100.0)$ & \\
\hline
\end{tabular}

\section{Discussion}

Determining the prevalence of infertility in general and male factor infertility in particular is vital. This study was aimed to determine the prevalence and patterns of male infertility in patients visiting Massawa Hospital outpatient department from June 2018 to June 2020.

The prevalence of male factor infertility on patients visiting Massawa hospital with infertility problems was found to be $42 \%$. This result was almost similar to other studies conducted by Boivin J et al 2007 [9] showed 50\%, Cooper TG et al. 2010[4] reported 40-50\%, ÜnalÖztekin et al. 2019[7] showed 45.6\%, Somé Nagaonlé Eric et al 2016;35.7\% [10] and Toragall MM et al. 2019; 50\%. [14] This higher prevalence of male infertility could be mainly due to different social, environmental and psychological factors among the study participants which need detailed analysis and evaluation of the problem. 
Majority (79.5\%) of the study participants had primary type of male infertility and was common in patients aged $<30$ years. This was almost similar to a study conducted by ÜnalÖztekin et al. 2019 that primary infertility was determined in $77.3 \%$ patients. [7] But it was higher to another study that primary infertility concerned $52.3 \%$ of men. [10] This study further showed that about half of the study participants with infertility complaints were below the age of 30 years.

The higher prevalence of primary type of infertility in the young group of population could have different causes as social factors; smoking and working environment which need further prospective research to identify the determinants of infertility problem.

This research showed that majority of the patients (56.3\%) had low sperm count of $<15$ million sperms $/ \mathrm{ml}$ and $12.5 \%$ had azospermia and patients aged 20 to 30 years had lower sperm count compared to the other age groups. This was lower to a study conducted by Mehta et al. that prevalence of azospermia in Kurnool and Jodhpur was 38.2\% and 37.3\% respectively. [11] Study conducted in Jaipur, Rajasthan reveals that prevalence of maximum number of infertile males was azospermic (35\%). [12] But this result was higher to other studies that $10.3 \%$ [7] and 5.85\%) [13] of males was azoospermic.

Most of the study participants (64.3\%) had sperm motility of $<40 \%$ and it was highly pronounced on those aged 20 to 30 years and commonly associated with primary type of infertility. This was higher to other study that, low sperm motility was recorded as (30.09\%). [14] This lower sperm count initiates for prospective studies to determine the risk factors.

Even though most of patients had semen volume of above $1.5 \mathrm{ml}$, they had relatively low sperm count; thus the absolute sperm count was reduced. Most patients aged 20 to 30 years had relatively reduced sperm count and motility; but this age group had higher semen volume compared to the other age groups. This could be mainly explained that; the young age group could have social habits as smoking and tobacco use which could affect the quality and quantity of their sperm.

\section{Limitations}

As the study was retrospective type based on semen analysis results, the determinants of infertility were not evaluated. It was difficult to retrieve further back ground characteristics of the male patient as their type of work, duration of infertility and other social factors from their medical records to associate with their semen analysis results. This prevalence of male factor infertility in Massawa Hospital can't generalize the general male factor prevalence in the country.

\section{Conclusion}

The prevalence of male factor infertility was relatively higher associated with primary type of infertility predominance and it was common in patients aged 20 to 30 years. Even though most patients had higher semen volume, the sperm analysis parameters (sperm count, motility and sperm morphology) were markedly decreased in majority of patients. 


\section{Recommendations}

Based on the findings, further prospective researches that determine the risk factors for male factor infertility, Comparative studies with different environmental and lifestyle factors, and determining the general prevalence of infertility in the country are highly recommended to evaluate the association and prevalence of infertility. Public awareness and health education on the potential lifestyle risks of male factor infertility are important to protect the community from the modifiable life style factors which could have direct or indirect effect on infertility. Based on the higher prevalence of male factor infertility; it is also time to announce assisted fertility in our country and to familiarize a specialized care of infertility or incorporate the comprehensive care to other existed programs.

\section{Declarations}

\section{Ethics approval and consent to participate}

Ethical approval was obtained from the Ministry of Health ethical clearance committee and consent was taken from study participants.

\section{Consent to publish}

Not applicable

\section{Availability of data and materials}

Necessary data could be requested from the corresponding author as needed

\section{Acknowledgment}

Author's acknowledges the data collectors of Massawa Hospital laboratory staffs and patients who participate in the study.

\section{Funding}

The researchers had no any source fund for data collection or publication

\section{Competing of interest}

Authors declare that they didn't have any competing of interest

\section{Authors Contributions}

BT and HG have conceived and designed the study material. All authors have participated in approving the final proposal. BT and LA have participated in data collection and data entry. FK have analyzed the data and all authors have participated in data interpretation and drafting of the manuscript. The final 
version of the manuscript was finalized by BT, FK and HG; finally all authors have reviewed and approved the final manuscript.

\section{Authors' information}

Berhe Tesfai, Medical Doctor, Medical Director of Massawa Hospital, Ministry of Health, Massawa, Eritrea. Email: berhetesfai04@gmail.com

Hailemichael Gebremariam, Medical Doctor, Dekemhare Hospital, Ministry of Health, Dekemhare, Eritrea, Email: gm.haile19@gmail.com

Fitsum Kibreab, MSc, Statistician, Policy, Planning, Research Resource center Ministry of Health, Asmara, Eritrea. Email: fachekg4@gmail.com

Liwam Abraham, Clinical Laboratory Science, Massawa Hospital, Ministry of Health, Massawa, Eritrea, Email: abelabarham@gmail.com

\section{References}

1. Prevalence and risk factors of infertility in turkey: evidence from demographic and health surveys, 1993-2013. Sarac M, Koc I. J Biosoc Sci. 2018;50:472-490.

2. Evaluation of 172 candidate polymorphisms for association with oligozoospermia or azoospermia in a large cohort of men of European descent. Aston KI, Krausz C, Laface I, Ruiz-Castané E, Carrell DT. Hum Reprod. 2010;25:1383-1397.

3. Sharma A (2017) Male Infertility; Evidences, Risk Factors, Causes, Diagnosis and Management in Human. Ann Clin Lab Res Vol.5:No. 3:188. doi: 10.21767/2386-5180.1000188.

4. Cooper TG, Noonan E, von Eckardstein S, Auger J, Baker HW, Behre HM, et al. World Health Organization reference values for human semen characteristics. Hum Reprod Update 2010;16:231-45

5. Sabra SM, Al-Harbi MS. An influential relationship of seminal fluid microbial infections and infertility, Taif Region, KSA. World J Med Sci 2014;10:32-7

6. N. Li, M. M. Jia, Y. Q. Peng, R. Ding. Semen quality pattern and age threshold: a retrospective crosssectional study of 71,623 infertile men in China, between 2011 and 2017; Reproductive Biology and Endocrinology; volume17, Number: 107 (2019)

7. ÜnalÖztekin, Mehmet Caniklioğlu, Sercan Sarı. Evaluation of Male Infertility Prevalence with Clinical Outcomes in Middle Anatolian Region.Cureus. 2019 Jul; 11(7): e5122.

8. Gebremariam Woldemicael. Recent fertility decline in Eritrea: Is it a conflict-led transition? Demographic research, volume 18, article 2, pages 27-58, 2008; DOI: 10.4054/DemRes.2008.18.2

9. Boivin J, Bunting L, Collins JA, Nygren KG. International estimates of infertility prevalence and treatment-seeking: potential need and demand for infertility medical care. Hum Reprod 2007; 22(6): 
1506-12.

10. Somé Nagaonlé Eric, Boncoungou Justine, Noël Poda Jean. Prevalence of the Infertility among Couples in Ouagadougou (Burkina Faso): a Population-based Survey. The open public health journal, TOPHJ-9-88: 2016: 9,88-97

11. Mehta RH, Makwana S, Ranga GM, Srinivasan RJ, Virk SS (2006) Prevalences of oligozoospermia and azoospermia in male partners of infertile couples from different parts of India. Asian J Androl 8: 89-93.

12. Sharma A (2014) Impact of age, verified occupation and lifestyle on semen parameters of infertile males in Jaipur: A preliminary study International Journal of Health and Allied Sciences 3: 278-283.

13. Rajan R (1981) Male infertility. J ObstGynaecol India 804-809.

14. Toragall MM, Satapathy SK, Kadadevaru GG, Hiremath MB. Association of demographic and lifestyle factors with semen quality of men with fertility problems attending infertility center in North Karnataka. Indian J Med Spec 2019;10:79-83 